\title{
Risk factors of the Secondary Fractures for Osteoporotic Vertebral Compression Fractures after Percutaneous Vertebroplasty
}

\author{
Xiao-kui Kang \\ Liaocheng People's Hospital \\ Sheng-fu Guo \\ Liaocheng People's Hospital \\ Hui-xin Liu \\ Liaocheng People's Hospital \\ Li-li Huang \\ Liaocheng People's Hospital \\ Qun-long Jiang ( $\nabla$ qunlongjiang@163.com ) \\ Liaocheng People's Hospital
}

Research article

Keywords: Osteoporosis, Spinal fractures, Vertebroplasty, Secondary fracture

Posted Date: January 10th, 2020

DOl: https://doi.org/10.21203/rs.2.20610/v1

License: (9) This work is licensed under a Creative Commons Attribution 4.0 International License.

Read Full License 


\section{Abstract}

Background Percutaneous vertebroplasty related postoperative secondary fractures risk factors were not consistent in patients with osteoporotic vertebral compression Fractures. The purpose was to identify the risk factors of the secondary fractures for osteoporotic vertebral compression fractures after percutaneous vertebroplasty.

Methods Potential academic articles were identified from Cochrane Library, Medline, PubMed, Embase, ScienceDirect and other databases. The time range we retrieved from was that from the inception of electronic databases to August 2019. Gray studies were identified from the references of included literature reports. STATA version 11.0 (Stata Corporation, College Station, Texas, USA) was used to analyze the pooled data.

Results Fourteen studies involving 1910 patients, 395 of whom had secondary fracture following the surgery were included in this meta-analysis. The results of meta-analysis showed the risk factors of the secondary fractures for osteoporotic vertebral compression fractures after percutaneous vertebroplasty was related to bone mineral density $[\mathrm{WMD}=-0.518,95 \% \mathrm{Cl}(-0.784,-0.252), \mathrm{P}=0.000]$, cement leakage $[R R=0.596,95 \% \mathrm{Cl}(0.444,0.798), \mathrm{P}=0.001]$ and kyphosis after primary operation [WMD $=4.510,95 \% \mathrm{Cl}$ $(3.061,6.004), \mathrm{P}=0.000]$, but not to gender, age, body mass index (BMI), cement volume, thoracolumbar spine, and cement injection approaches.

Conclusions BMD, cement leakage and kyphosis after primary operation are the risk factors closely correlative to the secondary fracture after percutaneous vertebroplasty. There has not been enough evidence to support the association between the secondary fracture and gender, age, body mass index, cement volume, thoracolumbar spine, and cement injection approach.

\section{Introduction}

Osteoporosis is a systemic disease with progressive dicalcium and bone structure abnormality, which could result in compression fracture even under a slight external force (falling, lifting heavy objects, coughing violently).[1, 2] Spine, hip and distal radius are the predilection sites of osteoporotic fracture, but osteoporotic vertebral compression fracture (OVCF) is the most common one, accounting for more than $1 / 3[3-5]$. Patients with OVCF could have a series of symptoms such as back pain and kyphosis, which can seriously affect the quality of life of patients.[6] Furthermore, the OVCF has a slow healing, accompanied by a high rate of disability and death.[7] The traditional treatment methods include bed rest, drug analgesia, bracing external fixation, resulting in a vicious circle of decalcification of bone, progresses of severe pain, kyphotic deformity and increasing mortality[8]. Percutaneous vertebroplasty (PVP) can be used as early as possible in an emergency once OVCF is diagnosed and the patient's physical condition permits. Due to small trauma, less time in bed, quick relief of the pain. PVP, a technique of injecting bone cement into the target vertebral body, currently has become the characteristics of the main clinical treatment of OVCF, which obtained the identification of orthopedic 
physicians and patients. $[9,10]$ However, numerous clinical data have been confirmed that the incidence of non-surgical vertebral fractures was $8 \%-52 \%$, and $41 \%-69 \%$ of the secondary fractures occurred in the adjacent segment of the vertebral body.[11-13] Lin et al.[14] believe that the stiffness and other biomechanical factors of the injured vertebral bone cement injection lead to changes in biomechanics of the whole spine, resulting in significant changes in the pressure of adjacent vertebral body. Though, the bulk of the data showed that the gender (significantly more women than men), age (mainly 60 to 80 years old), bone mineral density (BMD), cement volume, cement leakage are the underlying inducements. PVP related risk factors of postoperative secondary fractures were not consistent in patients with OVCF.[15, 16] Therefore, we collected literatures on the related factors of vertebral fracture after PVP of OVCF patients, assessed the effects of these factors on vertebral secondary fractures through meta-analysis.

\section{Materials And Methods}

\section{Literature and search strategy}

The retrieved object was the research literature on the analysis of secondary fractures of OVCF following PVP operation published publicly in the electronic databases including PubMed, Cochrane Library, EMBASE, and Web of Science from the inception of electronic databases to August 2019. We retrieved the following keywords in combination with Boolean logic: osteoporosis, vertebral compression fracture, percutaneous vertebroplasty, subsequent fracture, secondary fractures. Beyond that, the research of the appraisal reference list was manually checked to determine other potential qualification trials. The process iterates until no more articles could be determined. The meta-analysis was based on acknowledged PRISMA guideline (the prioritized reported items for systematic review and meta-analysis).

\section{Inclusion and exclusion criteria}

The articles will be incorporated into the present meta-analysis if the literatures meet the following principles: (I) OVCF patients undergoing PVP surgery; (II) analysis of related risk factors for postoperative patients with secondary fractures; (III) one or more adequate data of the outcomes could be conducted statistical analysis;(IV) Non-English language publications, case reports, comments, letters, editorials, protocols, guidelines, and review papers were excluded; $(V)$ animal studies were excluded.

\section{Data extraction and outcome measures}

Two of the reviewers respectively extracted data from the included studies. The following essential information was captured冈the first author names, publication year, samples size, study design, and outcomes and other relevant data. The extracted data (median, range and the size of the trial, and MD and SD) was input into the designed standardized table 1 . When there are differences of opinion, another authority author has the final decision. The outcome measurements were gender, age, body mass index 
(BMI), bone mineral density (BMD), cement volume, cement leakage, thoracolumbar spine, cement injection approach, kyphosis after primary operation.

\section{Quality assessment and Statistical analysis}

Tool of Cochrane Bone, the Joint and Muscle Trauma Group and Newcastle-Ottawa Scale (NOS) were respectively conducted to evaluate the quality assessment of the included RCTs and non-RCTs. The literature quality evaluation was conducted separately by two reviewers. Consensus was reached through consultation for divergence. We use the STATA version 11.0 (Stata Corporation, College Station, Texas, USA) for statistical analyses. When $\mathrm{I}^{2} \llbracket 50 \%$, we consider the data has obvious heterogeneity, and We conduct an meta-analysis using random-effect model according to Cochrane Handbook for Systematic Reviews of Interventions (version 5.1.0). Otherwise, fixed-effect model was performed. The results of continuous outcomes (age, BMI, BMD, cement volume) were expressed as mean difference (MD) with 95\% confidence intervals (Cls). For discontinuous various outcomes (gender, cement injection approach, kyphosis after primary operation, thoracolumbar spine, cement leakage) risk ratio (RR) with $95 \%$ Cls was applied for the assessment.

\section{Results}

\section{Search results}

A total of 216 studies were identified as potentially relevant literature reports. 58 reports were removed because of duplication. By scanning the title and abstract, 130 reports were excluded according to the eligibility criteria. 14 reports are eliminated after browsing the full text. No additional studies were obtained after the reference review. Ultimately, 14 studies $[14,16-28]$ were eligible for data extraction and meta-analysis. The searching process is shown in Figure1.

\section{Outcomes of meta-analysis}

\section{Bone mineral density (BMD)}

We extracted the BMD value from three included articles. The results show that BMD was the risk factors closely correlative to the secondary fractures after percutaneous vertebroplasty (Heterogeneity $\mathrm{P}=0.908$, $\mathrm{I}^{2}=0.0 \%, \mathrm{MD}=-0.518,95 \% \mathrm{Cl}:-0.784$ to $-0.252, \mathrm{P}=0.000$; Figure2).

\section{Cement leakage}


Six articles have been demonstrated the relationship between the cement leakage and secondary fractures rate. There is no significant heterogeneity in the statistical results of the pooled literature $\left(I^{2}=42.4 \%, P=0.123\right)$. The result of the fixed effect model showed that the cement leakage could increase the incidence of new fractures $(\mathrm{RR}=0.596,95 \% \mathrm{Cl}$ : 0.444 to $0.798, \mathrm{P}=0.001$; Figure3).

\section{Kyphosis}

Three publications focus on the effect of postoperative kyphosis after primary operation on secondary fractures. Similar to the results described above, postoperative kyphosis angle of vertebra is closely related to the secondary fractures (Heterogeneity $P=0.472, \mathrm{I}^{2}=0.0 \%, \mathrm{MD}=4.510,95 \% \mathrm{Cl}: 3.016$ to 6.004 , $P=0.000 ;$ Figure4).

\section{Gender}

In eleven publications, 97 males and 248 females were enrolled in our meta-analysis respectively. No significant difference between the risk factor and the gender was found (Heterogeneity $\mathrm{P}=0.830, \mathrm{I}^{2}=$ $0.0 \%, \mathrm{RR}=0.962,95 \% \mathrm{Cl}: 0.768$ to $1.204, \mathrm{P}=0.733$; Figure5).

\section{Age}

The results of the meta-analysis showed that the age had no effect on postoperative new fractures of OVCF patients following PVP operation (Heterogeneity $P=0.724, \mathrm{I}^{2}=0.0 \%, \mathrm{MD}=1.127,95 \% \mathrm{Cl}:-0.013$ to 2.267, $\mathrm{P}=0.053$; Figure6).

\section{Cement volume}

No significant differences were observed between the cement volume and new fractures rate of OVCF patients following PVP operation ( $M D=-0.506,95 \% \mathrm{Cl}-1.171$ to $0.158 ; \mathrm{P}=0.135$, Figure 7 ) with obvious heterogeneity (heterogeneity $\mathrm{P}=0.0000, \mathrm{I}^{2}=90.8 \%$ ).

\section{Body Mass Index (BMI)}

The BMI was reported in eight studies. A random-effects model was performed with obvious heterogeneity $\left(I^{2}=75.4 \%, P=0.000\right)$. There is no statistical difference on the $\mathrm{BMI}(\mathrm{MD}=-0.662,95 \% \mathrm{Cl}$ : 


\section{Thoracolumbar spine}

Five studies concentrated on whether the primary fracture in thoracic lumbar segment effects on postoperative secondary fractures of PVP operation. There was no obvious heterogeneity $\left(\mathrm{I}^{2}=48.3 \%, \mathrm{P}=\right.$ 0.101); therefore, a fixed-effects model was applied. Pooling the results demonstrated that primary fracture in thoracic lumbar segment has no effect on secondary fractures after PVP $(R R=0.898,95 \% \mathrm{Cl}$ : 0.696 to $1.159, \mathrm{P}=0.409$; Figure9).

\section{Cement injection approach}

Two publications compared the secondary fracture rate of different cement injection approaches. The result show that different cement injection approaches are independent of secondary fractures (Heterogeneity $\mathrm{P}=0.489, \mathrm{I}^{2}=0.0 \%, \mathrm{RR}=1.76,95 \% \mathrm{Cl}$ : 0.795 to $3.931, \mathrm{P}=0.163$; Figure10).

\section{Discussion}

The aging process of the population has accelerated osteoporosis as one of the common diseases that endanger the health of the elderly, and OVCF are the main complications of the disease.[5] According to the literature, OVCF accounts for about $45 \%$ of all osteoporotic fractures.[29] PVP could not only relieve pain rapidly and effectively, but also shorten the hospitalization days and improve the life quality of OVCF patients.[30] Though, PVP has been widely used in the treatment of OVCF, the problem of secondary fractures following PVP surgery is widely concerned. The studies reported that the incidence of new fractures following PVP was 7.4-52\%.[31, 32] But PVP related risk factors of postoperative secondary fractures are not consistent in OVCF patients. The results of our meta-analysis show that the new fractures after PVP for OVCF patients was related to BMD, cement leakage and kyphosis after primary operation, but not to gender, age, $\mathrm{BMI}$, cement volume, thoracolumbar spine or cement injection approach.

Mudano et al.[33] believed that the risk of secondary fractures in patients after PVP was significantly higher than that of conservative treatment. By using spinal finite element model, scholars observed that the bone cement injection could reduce the physiological concave of vertebral endplate.[34] This process not only increased the vertebral body pressure by $19 \%$, but also reduced the flexibility of local spinal joints, and the load of adjacent segments increased by $17 \%$. Another explanation for the secondary fractures is that increased daily activity in postoperative patients aggrandize the stress of the vertebral body, resulting in higher risk of secondary fractures.[35] 
BMD, an important symbol of bone mass, could reflect the degree of osteoporosis. The study showed that patients with lower BMD were more likely to have secondary fractures after PVP.[35] The result of 104 cases of OVCF patients with PVP follow-up study shows that there are $51.9 \%$ of patients of postoperative recurrence of adjacent vertebral fracture. The BMD of the fracture group was -3.52 , the non-fracture group was - 2.91. Logistic regression analysis showed that there was a negative correlation between BMD and the risk of fracture of adjacent vertebral bodies, suggesting that the lower BMD, the higher risk of secondary fractures of the adjacent vertebral bodies.[36] The research of Lu in 155 patients with PVP showed that the probability of new osteoporotic fractures within 2 years after the operation was $27.7 \%$. [19] Furthermore, The BMD in the fracture group was significantly lower than that of no more fracture group $(-3.07$ versus $-2.24, p \otimes 0.05)$. The results of our meta-analysis confirmed that low BMD was a highrisk factor for postoperative secondary fractures of OVCF patients. It also has a higher risk of secondary fractures even without PVP in OVCF patients. This risk may be the natural progression of osteoporosis.

The association between the secondary fractures and the correction of vertebral kyphosis is uncertain. KANG et al.[16]found 20 out of 27 cases of secondary fractures were surgical vertebral body fractures. The larger angle of the kyphosis preoperatively was a risk factor for fracture. At the same time, the correction of postoperative kyphosis lead to the imbalance of the stress of the vertebral body, which also increases the risk of vertebral fracture. Lin et al.[14] considered that each degree rectification in the vertebral kyphosis could increase the risk of adjacent vertebral fractures by $9 \%$. However, Lunt et al.[37] reported that kyphosis corrections could reduce the incidence of adjacent fractures. Robert et al. [38]believes that the severity of kyphosis is associated with a subsequent fracture of the adjacent vertebral body. The results of present meta-analysis show that the rates of secondary fractures in patients with larger postoperative vertebral kyphosis is higher. Under normal conditions, the compression load of the spine was perpendicular to the endplate of the vertebral body, and the progressive kyphosis will result in a change in the distribution of the spinal load, thus increasing the incidence of vertebral secondary fractures.[35] Therefore, we believe it is more favorable to correct kyphotic deformity without causing complications.

During the operation of PVP, bone cement could be overflowed through fractures fissure of vertebral body when it is injected into bone cement.[39, 40] The study showed that the leakage of bone cement to the intervertebral space increased the risk of fracture of adjacent vertebral body.[35, 41] The following mechanism of bone cement leakage may lead to a recurrent fracture of the adjacent vertebral body: (I) when the bone cement leaks into the intervertebral space, the stress reduction of the injured vertebral disc leads to an increase in the stress of the adjacent vertebral body. (II) The leakage of bone cement could mechanically stimulate the endplate plate of the adjacent vertebral body, accelerate the degeneration of the disc, and further increase the risk of fracture of adjacent vertebral body. The results of our metaanalysis indicate that bone cement leakage could increase the incidence of vertebral secondary fractures.

The choice of unilateral or bilateral puncture in PVP operation is still controversial. Steinmann et al.[42] hold the point that there is no statistically significant difference in the efficacy and mechanical analysis of PVP by unilateral or bilateral pedicle puncture. VAN-MEIRHAEGHE et al.[43]found that the strength and 
stiffness of injured vertebrae could be restored by unilateral injection or bilateral injection, which had no significant effect on the stress of non-operative vertebral body. The present meta-analysis demonstrate that cement leakage is not a risk factors for the new fractures to PVP for OVCF patients.

Kim et al.[44]compared the different volume of bone cement injection in PVP operation showing that there was no correlation between the secondary fractures and volumes of bone cement injection. Our meta-analysis gets the same conclusion. In addition, some scholars believe that the vertebrae which close to the primary fracture site has higher risk, especially the vertebrae at the thoracolumbar junction. $[45,46]$ However, the result of meta-analysis show that whether the primary fracture is located in the thoracolumbar segment has no effect on the secondary fractures after the PVP. Ahn et al.[47] found that low BMI is a risk factor for new fractures of the hip and spine. Conversely, vertebral fractures are more likely to occur in overweight patients [48]. The present meta-analysis show that BMI is not a relevant risk factor. In theory, the elderly women are more likely to develop osteoporosis, which could result in vertebral secondary fractures following PVP operation. However, from our meta-analysis, the age and gender are not an independent risk factor. It may be due to the relatively small sample size of the included literature; the conclusion is still to be proved.

Our research has the following limitations: (I) the included literatures were retrospectively studies (II) The length of the follow-up time is different in each study, and the data collection is not comprehensive (III) The quality of the included literatures is uneven.

\section{Conclusion}

$\mathrm{BMD}$, cement leakage and kyphosis after primary operation are the risk factors closely correlative to the secondary fracture after PVP. There has not been enough evidence to support the association between the secondary fracture and gender,age $\mathrm{BM} \llbracket$ cement volumelthoracolumbar spine, and cement injection approach.

\section{Declarations}

\section{Acknowledgments}

None.

\section{Funding}

None.

\section{Conflict of Interest}


The authors have declared that no competing interests exist.

\section{Abbreviations}

$\mathrm{RCT}=$ randomized controlled trial, $\mathrm{MD}=$ mean difference, $\mathrm{RD}=$ Risk difference, $\mathrm{Cl}=$ confidence intervals, $\mathrm{SD}=$ standard deviation, NOS=Newcastle-Ottawa Scale, $\mathrm{PVP}=$ percutaneous vertebroplasty, OVCF= osteoporotic vertebral compression fracture, RCS = retrospective controlled study, $\mathrm{BMD}=$ Bone mineral density, $\mathrm{BMI}=$ Body Mass Index, PKP= percutaneous kyphoplasty.

\section{References}

1. Longo UG, Loppini M, Denaro L, Maffulli N, Denaro V. Conservative management of patients with an osteoporotic vertebral fracture: a review of the literature. The Journal of bone and joint surgery British volume. 2012;94(2):152-7. Epub 2012/02/11. doi: 10.1302/0301-620x.94b2.26894. PubMed PMID: 22323677.

2. Yang H, Pan J, Wang G. A review of osteoporotic vertebral fracture nonunion management. Spine. 2014;39(26 Spec No.):B4-6. Epub 2014/12/17. doi: 10.1097/brs.0000000000000538. PubMed PMID: 25504096.

3. Buchbinder R, Golmohammadi K, Johnston RV, Owen RJ, Homik J, Jones A, et al. Percutaneous vertebroplasty for osteoporotic vertebral compression fracture. The Cochrane database of systematic reviews. 2015;(4):Cd006349. Epub 2015/04/30. doi: 10.1002/14651858.CD006349.pub2. PubMed PMID: 25923524.

4. Knopp-Sihota JA, Newburn-Cook CV, Homik J, Cummings GG, Voaklander D. Calcitonin for treating acute and chronic pain of recent and remote osteoporotic vertebral compression fractures: a systematic review and meta-analysis. Osteoporosis international : a journal established as result of cooperation between the European Foundation for Osteoporosis and the National Osteoporosis Foundation of the USA. 2012;23(1):17-38. Epub 2011/06/11. doi: 10.1007/s00198-011-1676-0. PubMed PMID: 21660557.

5. Shi GH, Li PC, Wei XC. [Progress on treatment of osteoporotic vertebral compression fracture]. Zhongguo gu shang $=$ China journal of orthopaedics and traumatology. 2013;26(10):878-82. Epub 2014/02/05. PubMed PMID: 24490543.

6. Ishikawa Y, Miyakoshi N, Kasukawa Y, Hongo M, Shimada Y. Spinal curvature and postural balance in patients with osteoporosis. Osteoporosis international : a journal established as result of cooperation between the European Foundation for Osteoporosis and the National Osteoporosis Foundation of the USA. 2009;20(12):2049-53. Epub 2009/04/04. doi: 10.1007/s00198-009-0919-9. PubMed PMID: 19343468.

7. Liu-Ambrose T, Eng JJ, Khan KM, Mallinson A, Carter ND, McKay HA. The influence of back pain on balance and functional mobility in 65- to 75-year-old women with osteoporosis. Osteoporosis international : a journal established as result of cooperation between the European Foundation for 
Osteoporosis and the National Osteoporosis Foundation of the USA. 2002;13(11):868-73. Epub 2002/11/05. doi: 10.1007/s001980200119. PubMed PMID: 12415433.

8. Silverman SL. The clinical consequences of vertebral compression fracture. Bone. 1992;13 Suppl 2:S27-31. Epub 1992/01/01. PubMed PMID: 1627411.

9. Kallmes DF, Jensen ME. Percutaneous vertebroplasty. Radiology. 2003;229(1):27-36. Epub 2003/10/02. doi: 10.1148/radiol.2291020222. PubMed PMID: 14519867.

10. Baerlocher MO, Saad WE, Dariushnia S, Barr JD, McGraw JK, Nikolic B. Quality improvement guidelines for percutaneous vertebroplasty. Journal of vascular and interventional radiology : JVIR. 2014;25(2):165-70. Epub 2013/11/19. doi: 10.1016/j.jvir.2013.09.004. PubMed PMID: 24238815.

11. Trout AT, Kallmes DF, Kaufmann TJ. New fractures after vertebroplasty: adjacent fractures occur significantly sooner. AJNR American journal of neuroradiology. 2006;27(1):217-23. Epub 2006/01/19. PubMed PMID: 16418388.

12. Hiwatashi A, Westesson PL. Patients with osteoporosis on steroid medication tend to sustain subsequent fractures. AJNR American journal of neuroradiology. 2007;28(6):1055-7. Epub 2007/06/16. doi: 10.3174/ajnr.A0519. PubMed PMID: 17569956.

13. Frankel BM, Monroe T, Wang C. Percutaneous vertebral augmentation: an elevation in adjacent-level fracture risk in kyphoplasty as compared with vertebroplasty. The spine journal : official journal of the North American Spine Society. 2007;7(5):575-82. Epub 2007/10/02. doi: 10.1016/j.spinee.2006.10.020. PubMed PMID: 17905320.

14. Lin WC, Cheng TT, Lee YC, Wang TN, Cheng YF, Lui CC, et al. New vertebral osteoporotic compression fractures after percutaneous vertebroplasty: retrospective analysis of risk factors. Journal of vascular and interventional radiology : JVIR. 2008;19(2 Pt 1):225-31. Epub 2008/03/18. doi: 10.1016/j.jvir.2007.09.008. PubMed PMID: 18341954.

15. Levy H, Seydafkan S, Rice JD, Easley KA, Tangpricha V. Comparative efficacy of vertebroplasty, kyphoplasty, and medical therapy for vertebral fractures on survival and prevention of recurrent fractures. Endocrine practice : official journal of the American College of Endocrinology and the American Association of Clinical Endocrinologists. 2012;18(4):499-507. Epub 2012/03/24. doi: 10.4158/ep11349.or. PubMed PMID: 22440996.

16. Kang SK, Lee CW, Park NK, Kang TW, Lim JW, Cha KY, et al. Predictive risk factors for refracture after percutaneous vertebroplasty. Annals of rehabilitation medicine. 2011;35(6):844-51. Epub 2012/04/17. doi: 10.5535/arm.2011.35.6.844. PubMed PMID: 22506213; PubMed Central PMCID: PMCРMС3309392.

17. Yoo CM, Park KB, Hwang SH, Kang DH, Jung JM, Park IS. The analysis of patterns and risk factors of newly developed vertebral compression fractures after percutaneous vertebroplasty. Journal of Korean Neurosurgical Society. 2012;52(4):339-45. Epub 2012/11/08. doi: 10.3340/jkns.2012.52.4.339. PubMed PMID: 23133722; PubMed Central PMCID: PMCPMC3488642.

18. Rho YJ, Choe WJ, Chun YI. Risk factors predicting the new symptomatic vertebral compression fractures after percutaneous vertebroplasty or kyphoplasty. European spine journal : official 
publication of the European Spine Society, the European Spinal Deformity Society, and the European Section of the Cervical Spine Research Society. 2012;21(5):905-11. Epub 2011/12/14. doi: 10.1007/s00586-011-2099-5. PubMed PMID: 22160212; PubMed Central PMCID: PMCPMC3337901. 19. Lu K, Liang CL, Hsieh CH, Tsai YD, Chen HJ, Liliang PC. Risk factors of subsequent vertebral compression fractures after vertebroplasty. Pain medicine (Malden, Mass). 2012;13(3):376-82. Epub 2012/01/10. doi: 10.1111/j.1526-4637.2011.01297.x. PubMed PMID: 22222166.

20. Ren HL, Jiang JM, Chen JT, Wang JX. Risk factors of new symptomatic vertebral compression fractures in osteoporotic patients undergone percutaneous vertebroplasty. European spine journal : official publication of the European Spine Society, the European Spinal Deformity Society, and the European Section of the Cervical Spine Research Society. 2015;24(4):750-8. Epub 2015/02/04. doi: 10.1007/s00586-015-3786-4. PubMed PMID: 25645589.

21. Sun G, Tang H, Li M, Liu X, Jin P, Li L. Analysis of risk factors of subsequent fractures after vertebroplasty. European spine journal : official publication of the European Spine Society, the European Spinal Deformity Society, and the European Section of the Cervical Spine Research Society. 2014;23(6):1339-45. Epub 2013/11/21. doi: 10.1007/s00586-013-3110-0. PubMed PMID: 24253933.

22. Li YA, Lin CL, Chang MC, Liu CL, Chen TH, Lai SC. Subsequent vertebral fracture after vertebroplasty: incidence and analysis of risk factors. Spine. 2012;37(3):179-83. Epub 2011/01/18. doi: 10.1097/BRS.0b013e3181f72b05. PubMed PMID: 21240045.

23. Voormolen $M H$, Lohle PN, Juttmann JR, van der Graaf Y, Fransen H, Lampmann LE. The risk of new osteoporotic vertebral compression fractures in the year after percutaneous vertebroplasty. Journal of vascular and interventional radiology : JVIR. 2006;17(1):71-6. Epub 2006/01/18. doi: 10.1097/01.rvi.0000190910.43602.3c. PubMed PMID: 16415135.

24. Martinez-Ferrer A, Blasco J, Carrasco JL, Macho JM, Roman LS, Lopez A, et al. Risk factors for the development of vertebral fractures after percutaneous vertebroplasty. Journal of bone and mineral research : the official journal of the American Society for Bone and Mineral Research. 2013;28(8):1821-9. Epub 2013/02/22. doi: 10.1002/jbmr.1899. PubMed PMID: 23427068.

25. Lin H, Bao LH, Zhu XF, Qian C, Chen X, Han ZB. Analysis of recurrent fracture of a new vertebral body after percutaneous vertebroplasty in patients with osteoporosis. Orthopaedic surgery. 2010;2(2):11923. Epub 2010/05/01. doi: 10.1111/j.1757-7861.2010.00074.x. PubMed PMID: 22009926.

26. Ahn Y, Lee JH, Lee HY, Lee SH, Keem SH. Predictive factors for subsequent vertebral fracture after percutaneous vertebroplasty. Journal of neurosurgery Spine. 2008;9(2):129-36. Epub 2008/09/04. doi: 10.3171/spi/2008/9/8/129. PubMed PMID: 18764744.

27. Lee WS, Sung KH, Jeong HT, Sung YS, Hyun YI, Choi JY, et al. Risk factors of developing new symptomatic vertebral compression fractures after percutaneous vertebroplasty in osteoporotic patients. European spine journal : official publication of the European Spine Society, the European Spinal Deformity Society, and the European Section of the Cervical Spine Research Society. 2006;15(12):1777-83. Epub 2006/07/22. doi: 10.1007/s00586-006-0151-7. PubMed PMID: 16858596. 
28. Lo YP, Chen WJ, Chen LH, Lai PL. New vertebral fracture after vertebroplasty. The Journal of trauma. 2008;65(6):1439-45. Epub 2008/12/17. doi: 10.1097/TA.0b013e318169cd0b. PubMed PMID: 19077639.

29. Heini PF, Walchli B, Berlemann U. Percutaneous transpedicular vertebroplasty with PMMA: operative technique and early results. A prospective study for the treatment of osteoporotic compression fractures. European spine journal : official publication of the European Spine Society, the European Spinal Deformity Society, and the European Section of the Cervical Spine Research Society. 2000;9(5):445-50. Epub 2000/11/01. PubMed PMID: 11057541; PubMed Central PMCID: PMCPmc3611376.

30. Grados F, Depriester C, Cayrolle G, Hardy N, Deramond H, Fardellone P. Long-term observations of vertebral osteoporotic fractures treated by percutaneous vertebroplasty. Rheumatology (Oxford, England). 2000;39(12):1410-4. Epub 2001/01/04. PubMed PMID: 11136886.

31. Movrin I, Vengust R, Komadina R. Adjacent vertebral fractures after percutaneous vertebral augmentation of osteoporotic vertebral compression fracture: a comparison of balloon kyphoplasty and vertebroplasty. Archives of orthopaedic and trauma surgery. 2010;130(9):1157-66. Epub 2010/05/08. doi: 10.1007/s00402-010-1106-3. PubMed PMID: 20449750.

32. Fribourg D, Tang C, Sra P, Delamarter R, Bae H. Incidence of subsequent vertebral fracture after kyphoplasty. Spine. 2004;29(20):2270-6; discussion 7. Epub 2004/10/14. PubMed PMID: 15480139.

33. Mudano AS, Bian J, Cope JU, Curtis JR, Gross TP, Allison JJ, et al. Vertebroplasty and kyphoplasty are associated with an increased risk of secondary vertebral compression fractures: a populationbased cohort study. Osteoporosis international : a journal established as result of cooperation between the European Foundation for Osteoporosis and the National Osteoporosis Foundation of the USA. 2009;20(5):819-26. Epub 2008/09/18. doi: 10.1007/s00198-008-0745-5. PubMed PMID: 18797812; PubMed Central PMCID: PMCPmc4089886.

34. Baroud G, Nemes J, Heini P, Steffen T. Load shift of the intervertebral disc after a vertebroplasty: a finite-element study. European spine journal : official publication of the European Spine Society, the European Spinal Deformity Society, and the European Section of the Cervical Spine Research Society. 2003;12(4):421-6. Epub 2003/04/11. doi: 10.1007/s00586-002-0512-9. PubMed PMID: 12687437; PubMed Central PMCID: PMCPmc3467784.

35. Uppin AA, Hirsch JA, Centenera LV, Pfiefer BA, Pazianos AG, Choi IS. Occurrence of new vertebral body fracture after percutaneous vertebroplasty in patients with osteoporosis. Radiology. 2003;226(1):119-24. Epub 2003/01/04. doi: 10.1148/radiol.2261011911. PubMed PMID: 12511679.

36. Kim MH, Lee AS, Min SH, Yoon SH. Risk factors of new compression fractures in adjacent vertebrae after percutaneous vertebroplasty. Asian spine journal. 2011;5(3):180-7. Epub 2011/09/06. doi: 10.4184/asj.2011.5.3.180. PubMed PMID: 21892391; PubMed Central PMCID: PMCPmc3159067.

37. Lunt M, O'Neill TW, Felsenberg D, Reeve J, Kanis JA, Cooper C, et al. Characteristics of a prevalent vertebral deformity predict subsequent vertebral fracture: results from the European Prospective Osteoporosis Study (EPOS). Bone. 2003;33(4):505-13. Epub 2003/10/14. PubMed PMID: 14555253. 
38. Tatsumi RL, Ching AC, Byrd GD, Hiratzka JR, Threlkeld JE, Hart RA. Predictors and prevalence of patients undergoing additional kyphoplasty procedures after an initial kyphoplasty procedure. The spine journal : official journal of the North American Spine Society. 2010;10(11):979-86. Epub 2010/10/26. doi: 10.1016/j.spinee.2010.08.027. PubMed PMID: 20970737.

39. Venmans A, Klazen CA, van Rooij WJ, de Vries J, Mali WP, Lohle PN. Postprocedural CT for perivertebral cement leakage in percutaneous vertebroplasty is not necessary-results from VERTOS II. Neuroradiology. 2011;53(1):19-22. Epub 2010/05/06. doi: 10.1007/s00234-010-0705-6. PubMed PMID: 20442991; PubMed Central PMCID: PMCPmc3016147.

40. Kalteis T, Luring C, Gugler G, Zysk S, Caro W, Handel M, et al. [Acute tissue toxicity of PMMA bone cements]. Zeitschrift fur Orthopadie und ihre Grenzgebiete. 2004;142(6):666-72. Epub 2004/12/23. doi: 10.1055/s-2004-832317. PubMed PMID: 15614645.

41. Bae JS, Park JH, Kim KJ, Kim HS, Jang IT. Analysis of Risk Factors for Secondary New Vertebral Compression Fracture Following Percutaneous Vertebroplasty in Patients with Osteoporosis. World neurosurgery. 2017;99:387-94. Epub 2016/12/26. doi: 10.1016/j.wneu.2016.12.038. PubMed PMID: 28012889.

42. Steinmann J, Tingey CT, Cruz G, Dai Q. Biomechanical comparison of unipedicular versus bipedicular kyphoplasty. Spine. 2005;30(2):201-5. Epub 2005/01/13. PubMed PMID: 15644756.

43. Van Meirhaeghe J, Bastian L, Boonen S, Ranstam J, Tillman JB, Wardlaw D. A randomized trial of balloon kyphoplasty and nonsurgical management for treating acute vertebral compression fractures: vertebral body kyphosis correction and surgical parameters. Spine. 2013;38(12):971-83. Epub 2013/03/01. doi: 10.1097/BRS.0b013e31828e8e22. PubMed PMID: 23446769; PubMed Central PMCID: PMCPmc3678891.

44. Kim DJ, Kim TW, Park KH, Chi MP, Kim JO. The proper volume and distribution of cement augmentation on percutaneous vertebroplasty. Journal of Korean Neurosurgical Society. 2010;48(2):125-8. Epub 2010/09/22. doi: 10.3340/jkns.2010.48.2.125. PubMed PMID: 20856660; PubMed Central PMCID: PMCPmc2941854.

45. Tanigawa N, Komemushi A, Kariya S, Kojima H, Shomura Y, Sawada S. Radiological follow-up of new compression fractures following percutaneous vertebroplasty. Cardiovascular and interventional radiology. 2006;29(1):92-6. Epub 2005/10/18. doi: 10.1007/s00270-005-0097-x. PubMed PMID: 16228846.

46. Chang CY, Teng MM, Wei CJ, Luo CB, Chang FC. Percutaneous vertebroplasty for patients with osteoporosis: a one-year follow-up. Acta radiologica (Stockholm, Sweden : 1987). 2006;47(6):568-73. Epub 2006/08/01. PubMed PMID: 16875334.

47. Thomas T, Barou O, Vico L, Alexandre C, Lafage-Proust MH. Recurrence of vertebral fracture with cyclical etidronate therapy in osteoporosis: histomorphometry and X-Ray microanalysis evaluation. Journal of bone and mineral research : the official journal of the American Society for Bone and Mineral Research. 1999;14(2):198-205. Epub 1999/02/05. doi: 10.1359/jbmr.1999.14.2.198. PubMed PMID: 9933473. 
48. Tanaka S, Kuroda T, Saito M, Shiraki M. Overweight/obesity and underweight are both risk factors for osteoporotic fractures at different sites in Japanese postmenopausal women. Osteoporosis international : a journal established as result of cooperation between the European Foundation for Osteoporosis and the National Osteoporosis Foundation of the USA. 2013;24(1):69-76. Epub 2012/12/12. doi: 10.1007/s00198-012-2209-1. PubMed PMID: 23229467.

\section{Table}

Table 1 Cohort characteristics.

\begin{tabular}{ccccccccc}
\hline Studies & Year & Country & Fractures & Simple size & Age & Type & Follow-up & NOS \\
& & & & & & & & \\
\hline Lee WS & 2006 & Korea & 38 & 244 & 66.4 & RCS & $\square 48^{*}$ & 7 \\
Li YA & 2012 & China & 63 & 166 & 73.4 & RCS & $12-60^{*}$ & 6 \\
Lin WC & 2008 & China & 14 & 29 & $56-77$ & RCS & - & 8 \\
Lo YP & 2008 & China & 15 & 220 & $53-97$ & RCS & $24-36^{*}$ & 8 \\
Lu K & 2012 & China & 34 & 155 & $43-94$ & RCS & $\square 24^{*}$ & 8 \\
Martinez & 2013 & Spain & 17 & 57 & $73.6 \pm 9.3$ & RCS & $6-39^{*}$ & 7 \\
Ren HL & 2015 & China & 21 & 182 & $49-91$ & RCS & $6-60^{\star}$ & 8 \\
Rho YJ & 2012 & Korea & 27 & 147 & $49-93$ & RCS & $12-73^{*}$ & 8 \\
Sun G & 2014 & China & 37 & 175 & $70.3 \pm 8.2$ & RCS & $\square 12^{*}$ & 8 \\
Kang SK & 2011 & Korea & 27 & 60 & 70 & RCS & $\square 12^{*}$ & 7 \\
Lin H & 2008 & China & 14 & 29 & 73.8 & RCS & $22.4^{\star}$ & 8 \\
Voormolen & 2006 & Dutch & 16 & 66 & $46-88$ & RCS & $\square 12^{*}$ & 6 \\
Ahn Y & 2008 & Korea & 45 & 95 & 69.3 & RCS & - & 8 \\
Yoo CM & 2012 & Korea & 49 & 244 & $48-93$ & RCS & $0.2-61.7^{*}$ & 8 \\
\hline
\end{tabular}

*month

\section{Figures}




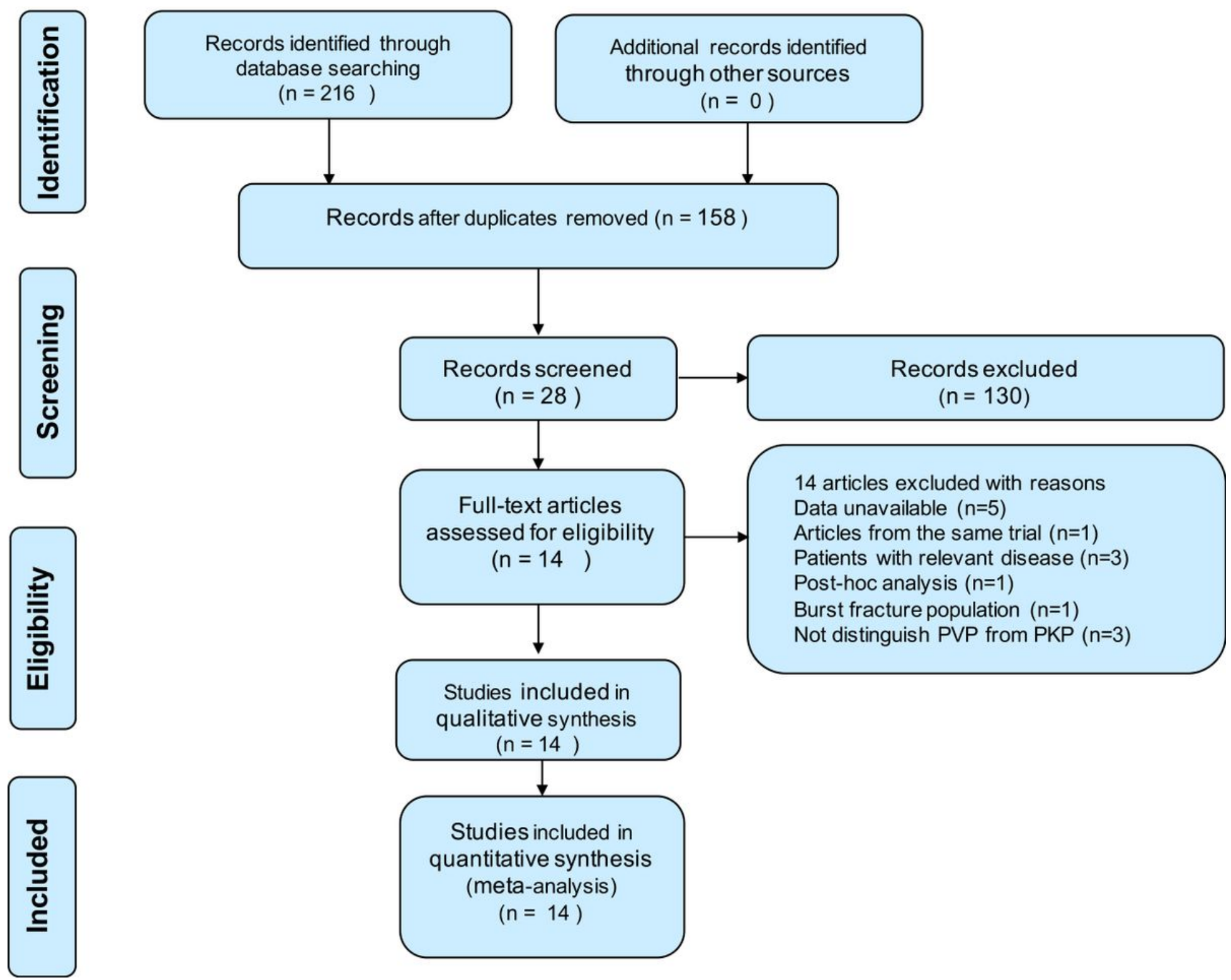

Figure 1

Flowchart of the study selection process 


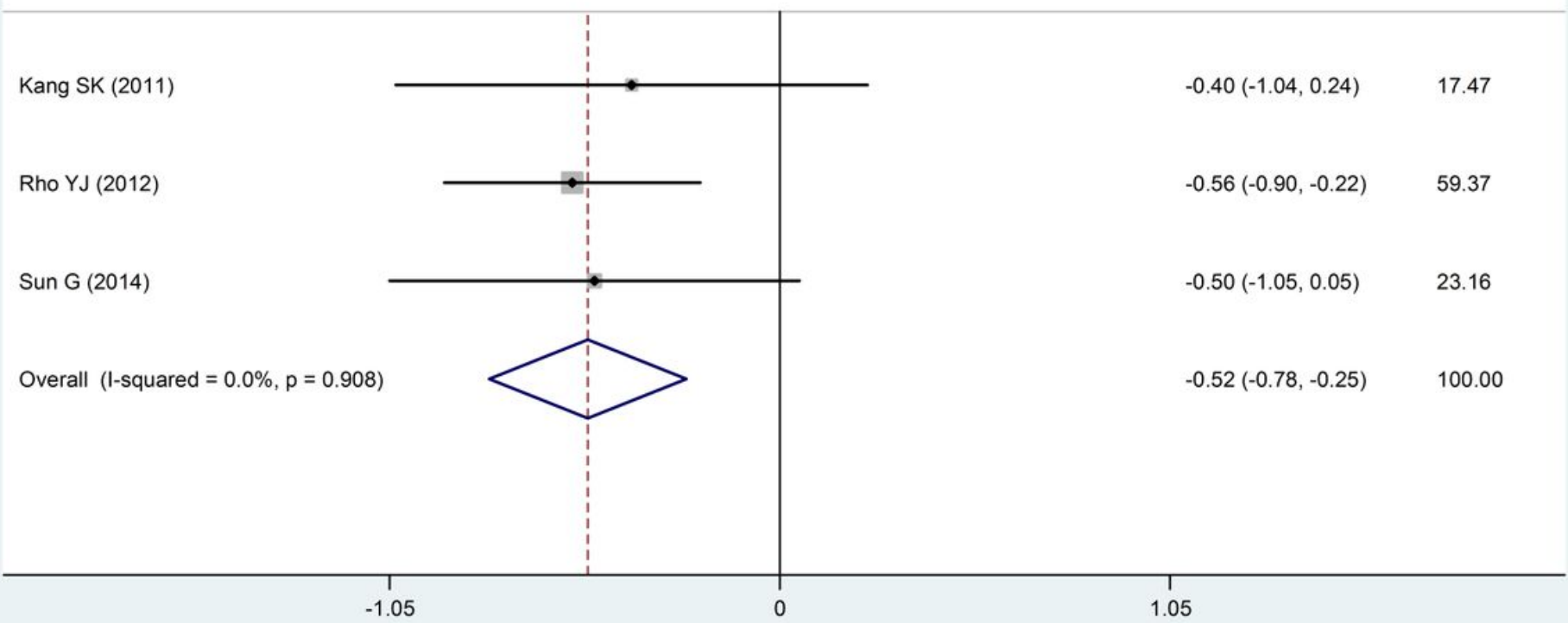

\section{Figure 2}

Forest plot diagram showing the BMD 


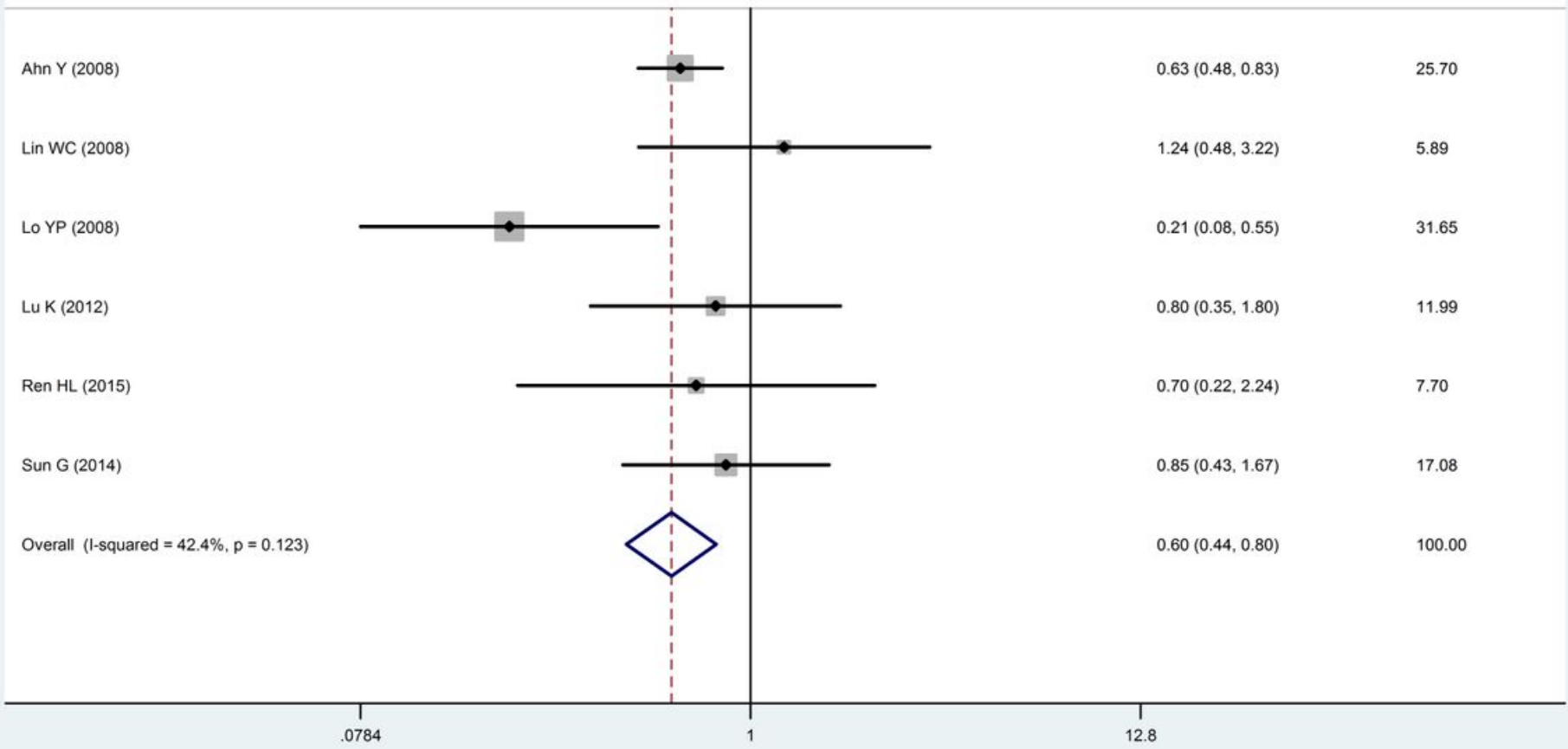

\section{Figure 3}

Forest plot diagram showing the cement leakage 


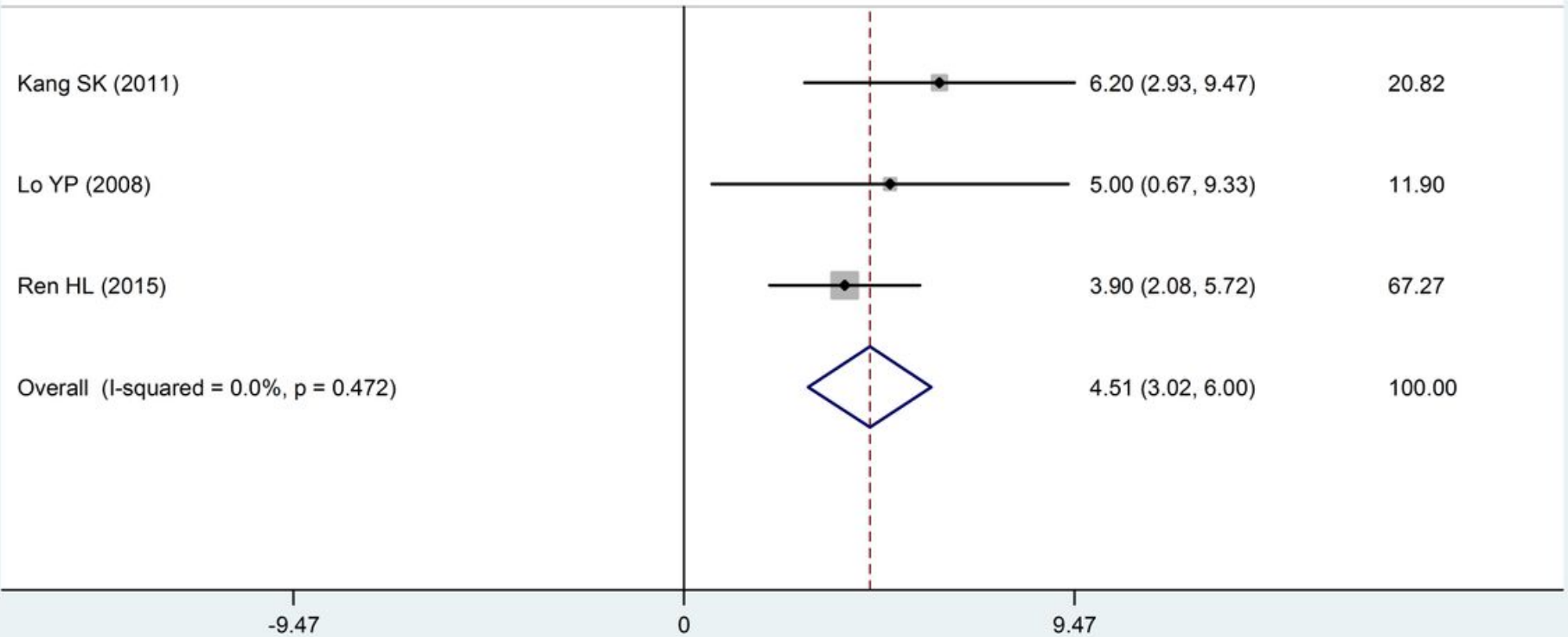

\section{Figure 4}

Forest plot diagram showing the kyphosis 
Study

ID

Lee WS (2008)

Li YA (2012)

Lin WC (2008)

Lo YP (2008)

Lu K (2012)

Martinez (2013)

Ren HL (2015)

Rho YJ (2012)

Sun G (2014)

Voormolen (2006)

Yoo CM (2012)

Overall (I-squared $=0.0 \%, p=0.830$ )
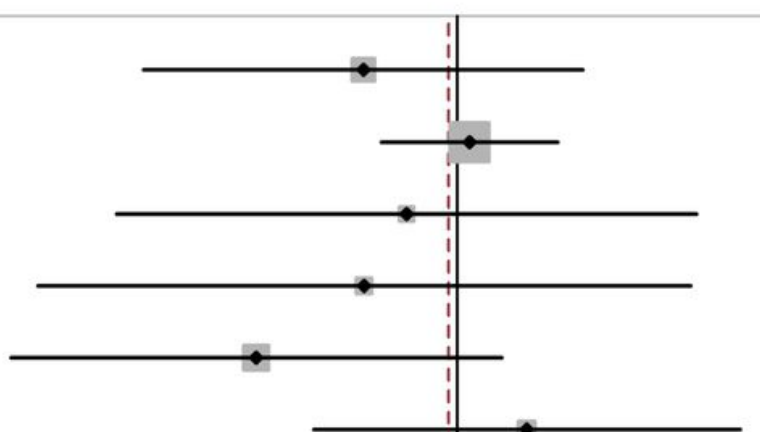

138
$\operatorname{RR}(95 \% \mathrm{Cl})$

$\%$

Weight

$0.66(0.25,1.75)$

$1.06(0.71,1.56) \quad 25.21$

$0.80(0.22,2.89) \quad 3.63$

$0.66(0.16,2.81) \quad 4.08$

$0.41(0.14,1.22) \quad 10.29$

$1.36(0.53,3.51) \quad 4.67$

$0.96(0.30,3.03) \quad 4.43$

$1.13(0.55,2.33) \quad 9.15$

$1.23(0.60,2.51) \quad 7.97$

$0.70(0.29,1.72) \quad 6.29$

$1.21(0.71,2.04) \quad 15.72$

$0.96(0.77,1.20) \quad 100.00$

\section{Figure 5}

Forest plot diagram showing the gender 
Study

ID

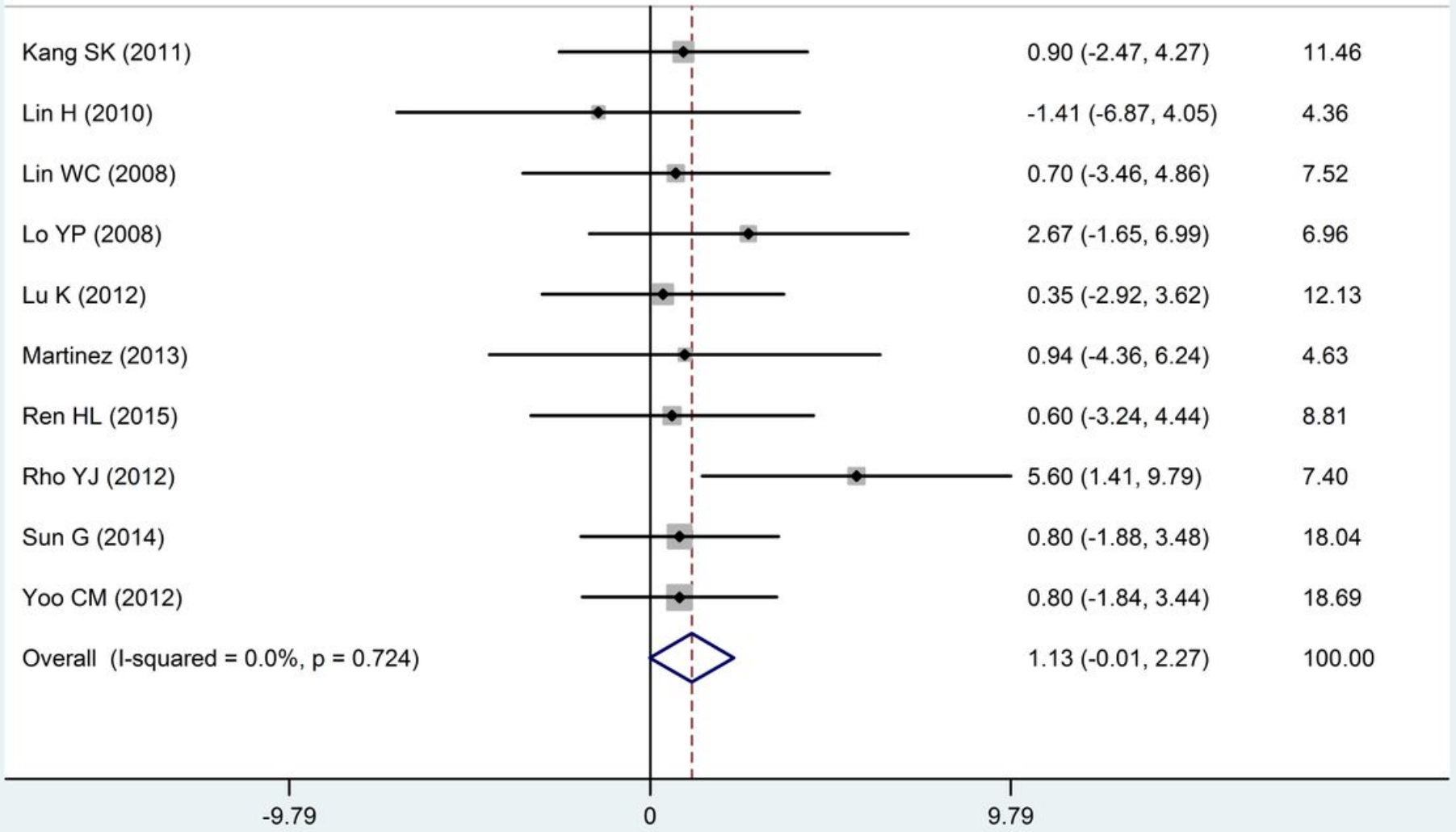

\section{Figure 6}

Forest plot diagram showing the age 


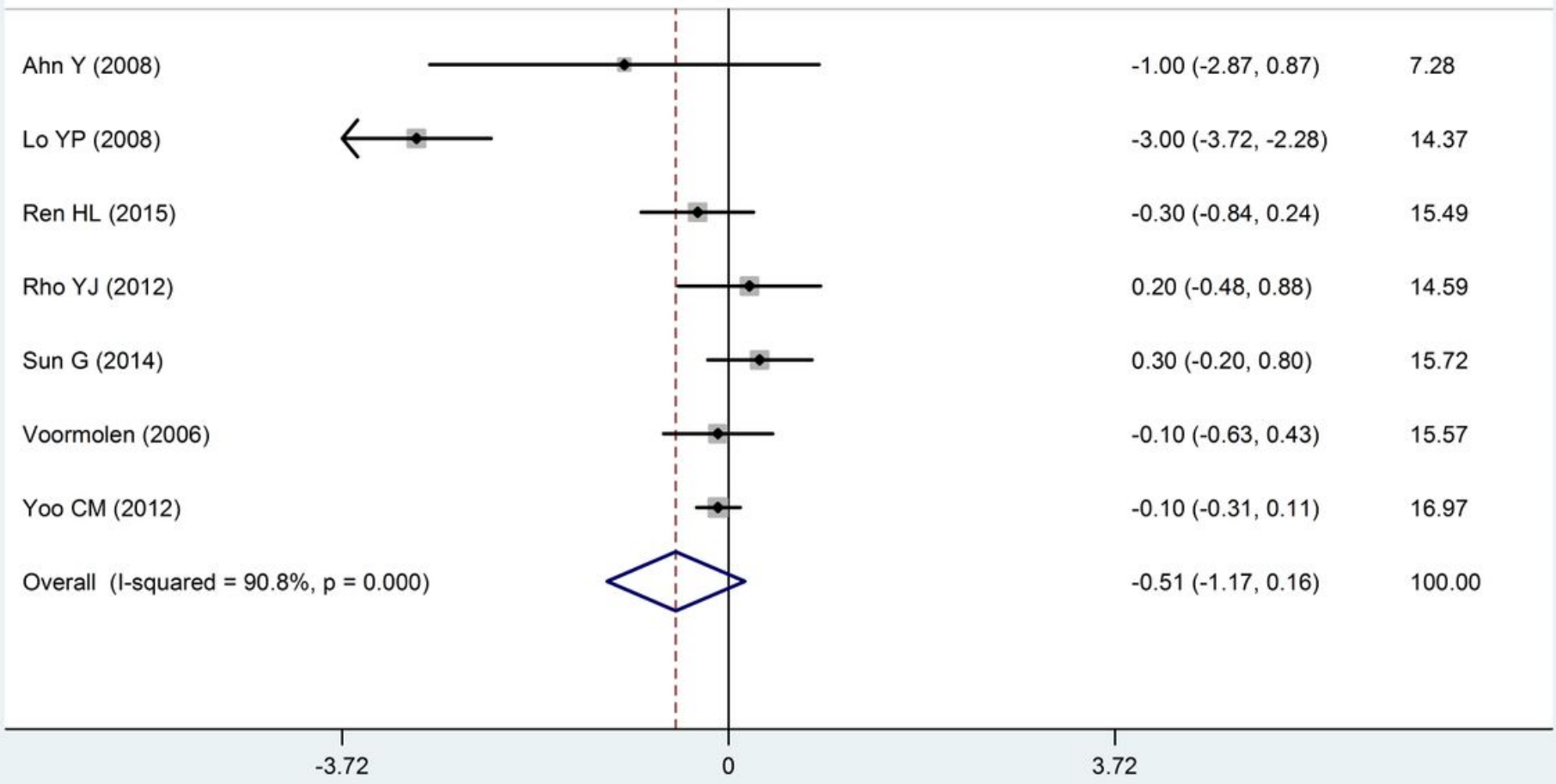

\section{Figure 7}

Forest plot diagram showing the cement volume 


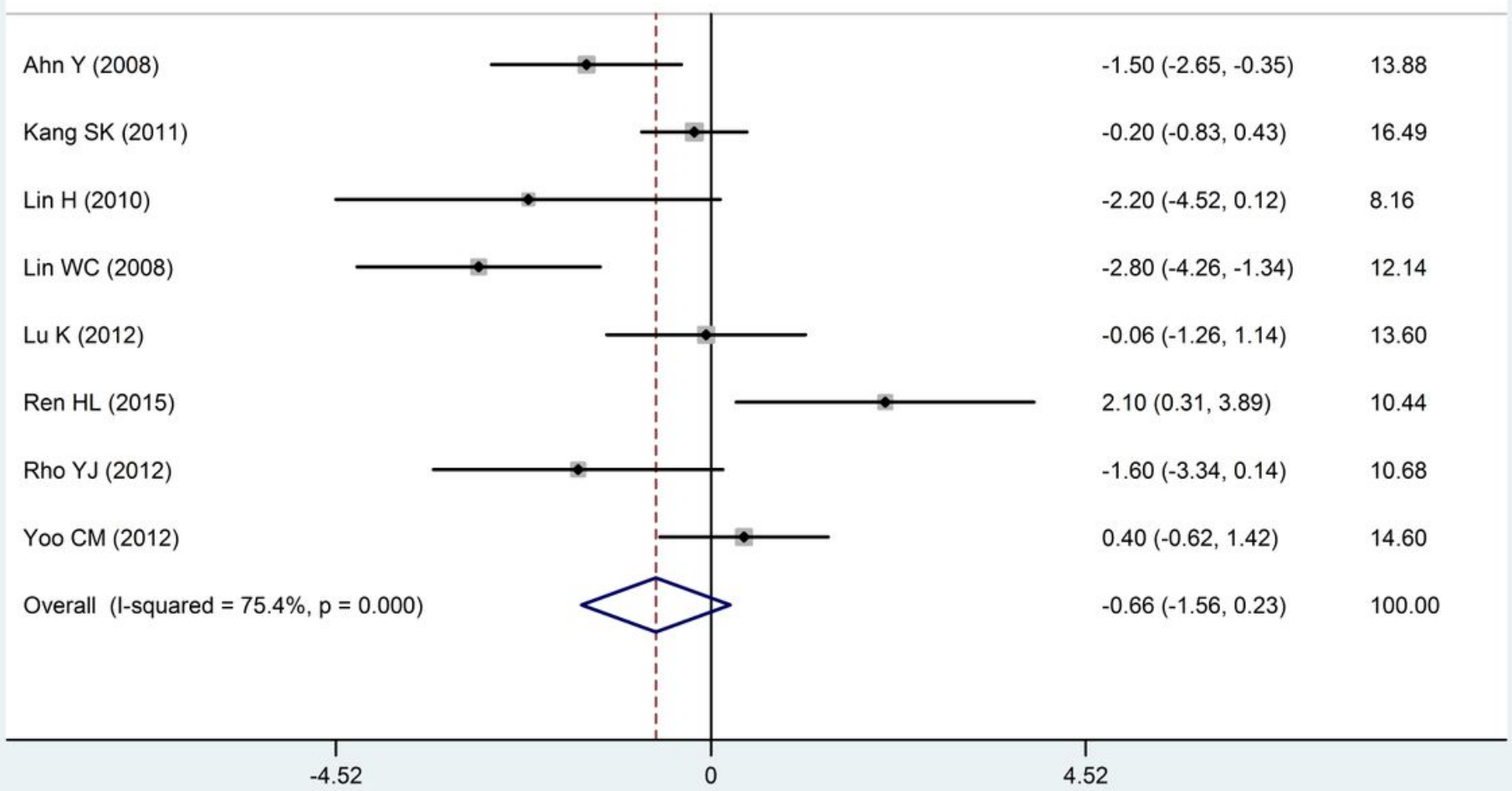

\section{Figure 8}

Forest plot diagram showing the BMI 


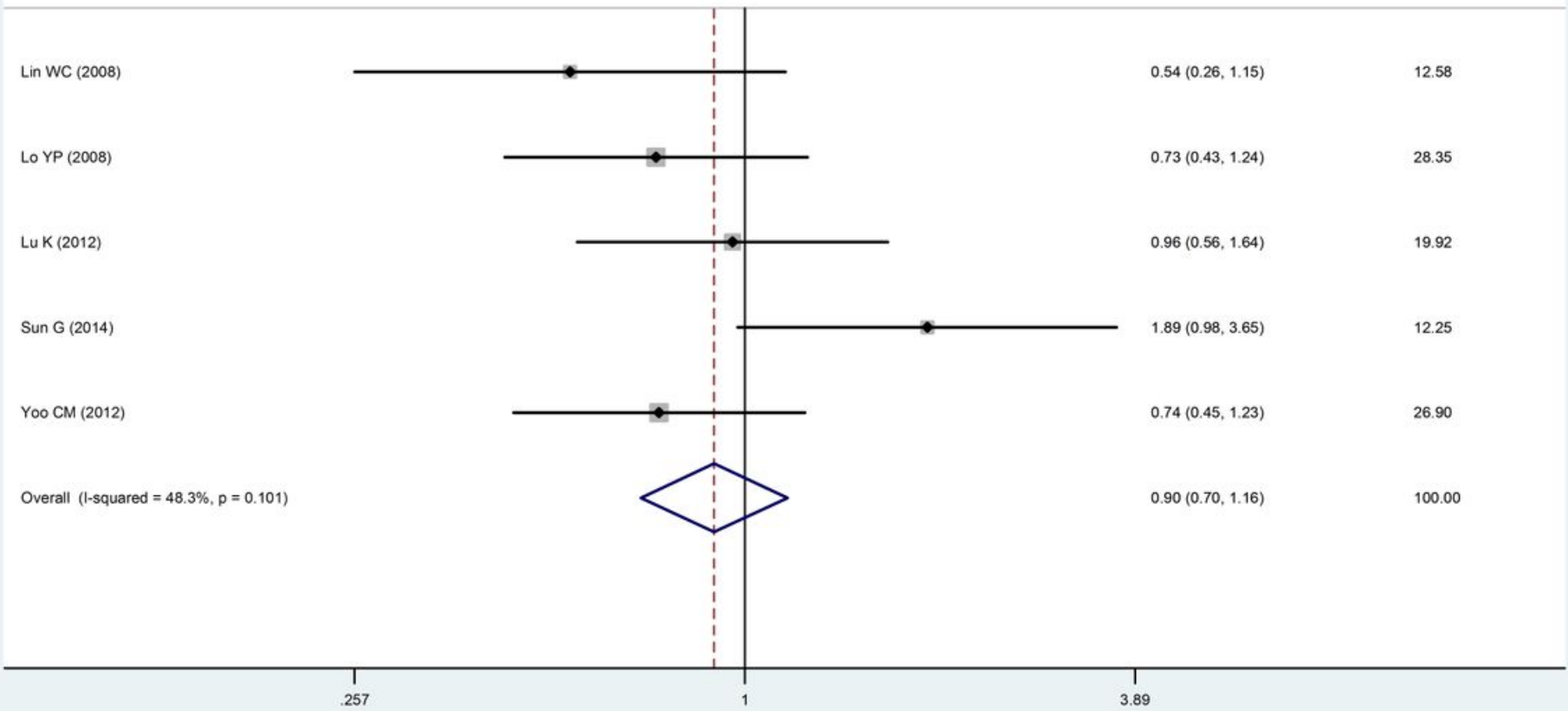

\section{Figure 9}

Forest plot diagram showing the thoracolumbar spine 


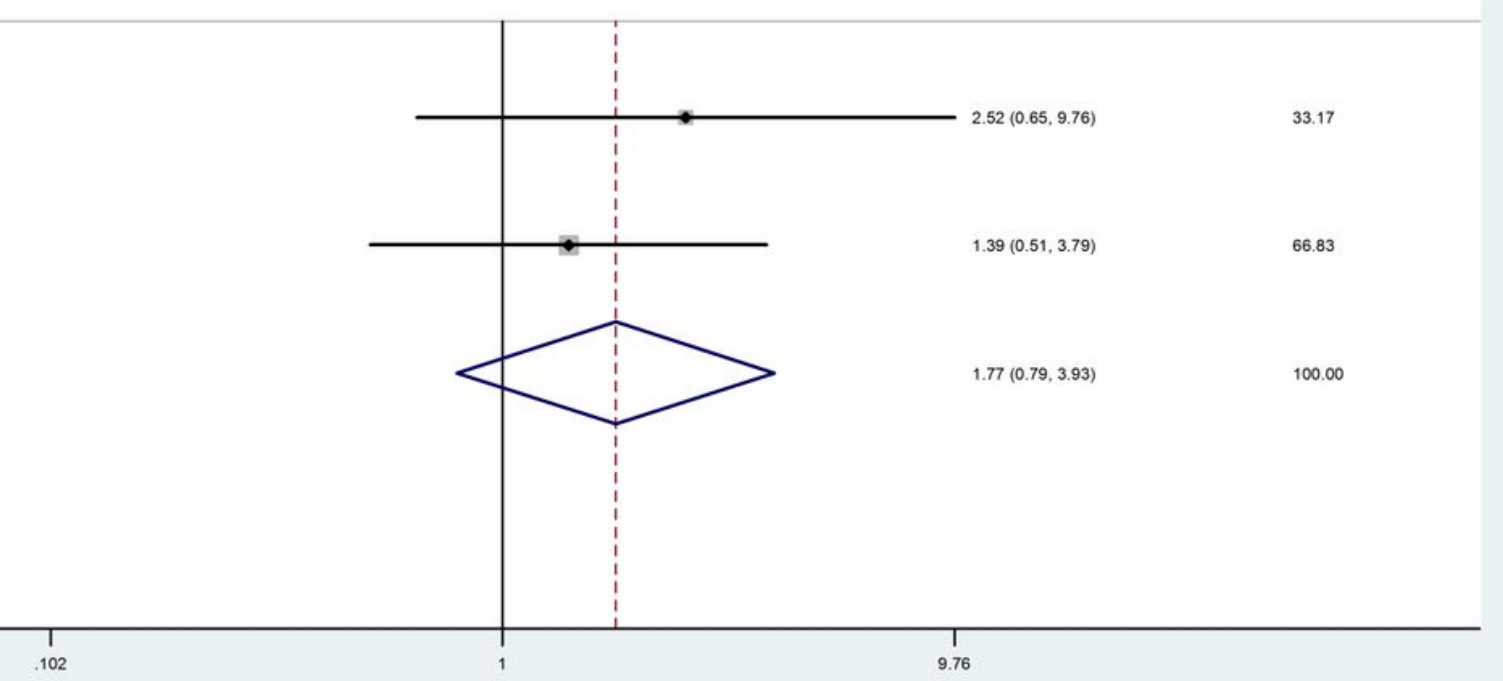

\section{Figure 10}

Forest plot diagram showing the cement injection approach

\section{Supplementary Files}

This is a list of supplementary files associated with this preprint. Click to download.

- PRISMAChecklist.doc 